\title{
Editorial
}

\section{Evolving Antibiotic Resistance: A Great Threat to Medical Practice}

\author{
Azad Chowdhury M.A.K.
}

\section{Introduction}

Presently for all clinicians \& surgeons, one of the greatest concern and anxiety is the emergence of drug resistance to the pathogenic organisms. Since last 80 years of antimicrobial use-from the sulphonamides of the 1930s to the present carbapenems-resistance always emerges, even when it is least expected.

Most of the important bacterial pathogens have developed resistance to the major antibacterial options and it is now a global healthcare threat. Clinical and economic impact of this is devastating, especially in developing countries like ours.

Recent estimates in the European Union for the costs of selected multidrug resistant bacteria are 25,000 deaths per year and 1.5 million EUR ${ }^{1}$. In the USA $\$ 20-30,000$ per patient excess hospital costs, excess social cost of 10-18 million and double the morbidity (attributable mortality 6.5\%) ${ }^{2}$. In a recent survey of European Intensive Care Unit physicians, $82 \%$ considered multidrug resistance to be the major problem ${ }^{3}$.

In developing countries including Bangladesh 70\% of hospital acquired neon. Unit infections cannot be treated with WHO recommended drugs ${ }^{4}$.

According to Dr. David Livermore of Healthcare Protection Agency, UK-an expert in this field,'Bacterial resistance will continue to become more complex. Thirty years ago, 11 different plasmid-mediated B-lactamases were known and from a single isoelectric focusing one could identify the enzyme present in any isolate with $>90 \%$ certainty. It was rare then for an isolate to have more than one acquired B-lactamase. Nowadays, over 250 acquired B-lactamases are known and it is commonplace for an isolate to have multiple enzymes or confusingly, multiple variants of the same enzyme. ${ }^{15}$

\section{Pneumococcal resistance}

Streptococcus pneumoniae remains one of the major pathogens in children and adults worldwide. Over the past 3 decades, antimicrobial resistance among
Streptococcus pneumoniae, the most common cause of community-acquired pneumonia (CAP), has escalated dramatically. Currently 15 to $30 \%$ of S. pneumoniae worldwide are multidrug-resistant (MDR) (i.e., resistant to 3 classes of antibiotics). Globally, it is estimated that, it is responsible for more than $5,000,000$ pneumonia and approximately 100,000 meningitis cases, the whole being associated with $10,000,000$ bacteremia cases every year. ${ }^{6}$

\section{Nosocomial MRSA}

Methicillin resistant S. aureus (MRSA) isolates were once confined largely to hospitals, other health care environments, and patients frequenting these facilities. Community-associated MRSA strains have rapidly disseminated among the general population in many countries and affect patients with and without exposure to the health care environment. Several studies have demonstrated increased mortality, length of hospitalization and hospital costs from infections due to MRSA.?

\section{Gram negative infections}

Unlike the West, where Gram positive infections are the problem, the Indian subcontinent is plagued by resistance in the Gram negative organisms. Drug resistant tuberculosis and malaria also add to our woes.

Gram negative organisms account for most of nosocomial infections. E. coli, Klebsiella, Pseudomonas and Acinetobacter are the main culprits.

Carbapenem and Ciprofloxacin resistance is $30 \%$ to $50 \%$. In general Fluoroquinolone resistance in Gram negative bacteremia is upwards of $70 \%{ }^{8}$

Salmonella is the third most common cause of bacteremia after E. coli and Klebsiella, contributing to over a quarter of cases. The evolution of therapy for Salmonella typhi and paratyphi reveal a growing resistance to the first line drugs such as Ampicillin, Chloramphenicol and Co-trimoxazole.

In our Dhaka Shishu Hospital, almost 100\% of these Gram negative organisms are now resistant to 
Ampicillin and Gentamycin. About a decade ago they were sensitive to 3 rd generation cephalosporins and ciprofloxacillin. ${ }^{9}$ But now-a-days nearly $70 \%$ are resistant and there is growing resistance to imipenem, meropenem.

\section{Risk factors associated with the increased inci- dence of resistance include}

- Unregulated antibiotic usage

- Poor sanitary standards

- Primitive infection control

- Prolonged hospital stay

- Increased severity of illness

- Invasive interventions

- Lack of technical infrastructure to generate data to define the resistance problem

Among many factors that can affect the emergence and spread of antimicrobial resistance, antimicrobial abuse or misuse is the most important and a basic driving force to induce the resistance. Antibiotics are the most common drugs to be used inappropriately and unreasonably as in the clinical practice, abuse or misuse of antibiotics may not result in immediate harm or problems to the patients.

\section{Current status of antimicrobial uses in Asia}

- In Turkey, $28 \%$ of the subjects were storing antibiotics at home. $19.1 \%$ of the subjects were taking antibiotics by themselves without any professional recommendations for sore throat, fever or cough. ${ }^{10}$

- In Japan, $60 \%$ of the patients who have visited clinics or hospitals were given antibiotics for non-bacterial URI. Third-generation cephalosporins were the most commonly prescribed drug class (46\%) followed by macrolides $(27 \%)$ and quinolones $(16 \%) .{ }^{11}$

- In China, recent data showed that $77.8 \%$ of inpatients were given antibiotics among which $55 \%$ were prescribed two or more kinds of antibiotics. In $58 \%$ of cases, antibiotics were given therapeutically, but only 39 out of 1,025 cases were investigated microbiologically. ${ }^{12}$

- In Korea, $54.7 \%$ of the physicians prescribed antibiotics for acute bronchitis, which was presumed viral infection. ${ }^{13}$

- In Hong Kong, several surveys showed that antibiotics are being prescribed for ca. 60-80\% of cold and flu outpatient visits.

- In Indonesia, 84\% of inpatients in two teaching hospitals received antibiotics. Therapeutic uses accounted for $53 \%$, prophylactic uses in $15 \%$ and unclear indication in $32 \%$ of cases. Overall, only $21 \%$ of antibiotics uses were evaluated appropriate. ${ }^{14}$

- In India, according to a recent survey, overall antibiotic prescription rate was $81.8 \%$ in primary and secondary healthcare facilities. It was significantly higher in rural hospitals than in urban hospitals. The most common antibiotics used were penicillin, sulphonamides, and fluoroquinolones. ${ }^{15}$

- In Bangladesh the picture is similar to India and majority of the pharmacists/drug-sellers advice and sell antibiotics without prescription.

Novel testing methods for determining antimicrobial resistance include real-time PCR, mass spectroscopy and next generation sequencing which are costly and not easily available in our developing countries.

\section{How to tackle}

To effectively tackle the major resistance problems legislative measures are required.

The interventions should target

- Regulation in the use of Antibiotics

- Increasing awareness about Resistance

- Standardizing effective surveillance

- Strengthening Infection Control to ensure effective isolation, hand hygiene compliance, environmental disinfection and antimicrobial stewardship.

Comprehensive strategies should be implemented to control and prevent the emergence and the spread of antimicrobial resistance. The most important strategy is to promote the appropriate use of antimicrobial agents in the clinical practice.

A national strategy should be a multi-faceted approach and include strengthening antibiotic resistance surveillance, developing and implementing antibiotic guidelines for practitioners, conducting antibiotic utilization studies, improving access to and upgrading the quality of microbiological diagnostic facilities, increasing public awareness of antibiotic resistance and controlling and regulating the use of antibiotics for both medicinal and non- 


\section{Evolving Antibiotic Resistance: A Great Threat to Medical Practice}

medicinal purposes.

As antimicrobial resistance can spread between different countries, international collaboration is also very important. WHO and international organizations such as ANSORP (Asian Network for Surveillance of Resistant Pathogens) and APFID (Asia Pacific Foundation for Infectious Diseases) as well as CDC in respective country should work together on this topic.

\section{$\underline{\text { References }}$}

1. European Centre for Disease Control and Prevention, European Medicines Agency (2009). The bacterial challenge - time to ReAct. Available from: http://www.ema.europa.eu/docs/en_GB/document_li brary/Report/2009/11/WC500008770.pdf

2. Roberts RR, Hota B, Ahmad I, Scott RD, Foster SD, Abbasi F, Schabowski S et al. Hospital and societal costs of antimicrobial-resistant infections in a Chicago teaching hospital: implications for antibiotic stewardship.

Clin infect Dis 2009; 49: 1175-1184. http://dx.doi.org/10.1086/605630, PMid:19739972

3. Lepape A, Monnet DL, on behalf of participating members of the European Society of Intensive Care Medicine (ESICM). Experience of European Intensive Care Physicians with infections due to antibiotic-resistant bacteria, 2009. Euro Surveill 2009; 14(45):pii=19393. http://www.eurosuveillance.org/ViewArticle.aspx? ArticleId=19393.

4. Zaidi AK, Huskins WC, Thaver D, Bhutta ZA, Abbas Z, Goldmann DA. Hospital-acquired neonatal infections in developing countries Lancet 2005; 365:11751188. http://dx.doi.org/10. 1016/S0140-6736(05) 71881-X

5. Gould I M. Costs of hospital-acquired methicillinresistant Staphylococcus aureus (MRSA) and its contol. Int J Antimicrob Agents 2006; 28:379-384. Livermore DM, Mushtaq S, Warner $\mathrm{M}$ et al. Antimicrob Agents Chemother 2010; 55: 390-4. PMid:21041502

6. Lee S, Lee K, Kang Y, Bae S. Prevalence of serotype and multidrug-resistance of Streptococcus pneumoniae respiratory tract isolates in 265 adults and 36 children in Korea, 2002-2005. Microb Drug Resist. 2010 Jun; 16(2):135-42. http://dx.doi.org/10.1089/mdr.2009.0114 PMid:20370508

7. Wang, H. Nosocomial MRSA: the classic threat in
Continued surveillance of antimicrobial resistance, serotypes and genotypes is crucial in providing information on the emergence of multiresistant clones.

Vaccination could be another important strategy to control the emergence of antimicrobial resistance. Pneumococcal conjugate vaccine is the best example to reduce the prevalence of antimicrobial resistance in bacterial pathogens.

the hospital continues. ISAAR, April 6-8, 2011, Seoul, Korea.

8. Shanti M, Sekar U. Multi-drug Resistant Pseudomonas aeruginosa and Acinetobacter baumannii infections among Hospitalized Patients: Risk factors and Outcomes; J Assoc Physicians India 2009; $57: 635-45$

9. Ahmed ASMNU, Chowdhury MAKA, Hoque M, Darmstadt GL. Clinical and bacteriological profile of neonatal septicemia in a tertiary level pediatric hospital in Bangladesh. IndianPediatr 2002; 39: 1034-39. PMid:12466574

10. Ilhan MN, Durukan E, Ilhan SO et al. Self-medication with antibiotics: questionnaire survey among primary care center attendants. Pharmcoepidemiol Drug Safety. 18; 1150-57, 2009, http://dx.doi.org/10.1002/pds.1829, PMid:19827009

11. Higashi $\mathrm{T}$, fukuhara $\mathrm{S}$. Antibiotic prescription for upper respiratory tract infection in Japan. Intern Med. 48;1369-75, 2009

http://dx.doi.org/10.2169/internalmedicine.48.1893 PMid:19687581

12. Hu S, Liu X, Peng Y. Assessment of antibiotic prescription in hospitalized patients at a Chinese hospital. J Infect. 46;161-3, 2003

http://dx.doi.org/10.1053/jinf.2002.1078 PMid:12643864

13. Kim NS, Jang SN, Jang SM. Factors influencing antibiotic prescribing of primary health physicians in acute upper respiratory infections. J Prev Med Public Health 38;1-8, 2005

14. Hadi U, Duerick DO, Lestart ES, et al. Audit of antibiotic prescribing in two governmental teaching hospitals in Indonesia. Clin Microbiol Infect. 14;698707, 2008 http://dx.doi.org/10.1111/j.1469-0691.2008.02014.x PMid:18558943

15. Kumar R, Indira K, Rizvi A, et al. Antibiotic prescribing practices in primary and secondary healthcare facilities in Uttar Pradesh, India. J Clin Pharm Therapeut. 33;625-34, 2008 http://dx.doi.org/10.1111/j.1365-2710.2008.00960.x PMid:19138240 